\title{
Design, Implementation and Assessment of a New Automatic Hydraulic Braking System
}

\author{
Prof. Dr. Sabry Allam ${ }^{1}$, Dr. Sabreen A. Abdelwahab ${ }^{2}$ and Hamdy Abo El daheb ${ }^{1}$ \\ ${ }^{1}$ Automotive Technology Department, Faculty of Industrial Education, \\ Helwan University, Cairo, Egypt \\ ${ }^{2}$ Production Technology Department, Faculty of Industrial Education \\ Helwan University, Cairo, Egypt.
}

\begin{abstract}
In this research, a new automatic braking system was designed and tested to prevent collisions between a driver's vehicle and obstacles (vehicles, pedestrians). The primary objective of this work is to develop a safety car braking system using ultrasonic sensor and to design a vehicle with that can manage less human attention to the driving. An appropriate mechanism was used to operate and control the brake system automatically and it different from the previous systems which operate brake pedal according to signals incoming. A suitable electric pump is used to provide fluid flow and pressure value and two solenoid valves are used to control the direction of brake fluid in the hydraulic brake system.
\end{abstract}

The proposed system operated using three parts; sensing part, the second part depends on using a control unit and another part depends on a suitable actuator. It can detect the distance between obstacles and the driver's vehicle by the ultrasonic sensor and using a hydraulic pump and solenoids valves to operate the brake system if the driver does not push the brake pedal in the right time to stop the vehicle, this system can automatically stop the vehicle without driver input. The performance of the system was excellent and the errors between measured braking time and theoretical braking time were between one and two percent.

Keywords: Automatic braking system, Control program, Ultrasonic sensor, Braking distance.

\section{GENERAL INTRODUCTION}

The brake system is the most important system in vehicles that converts the kinetic energy of the moving vehicle into thermal energy while stopping it. The basic functions of a brake system are to slow the speed of the vehicle, to maintain its speed during downhill operation, and to hold the vehicle stationary after it has come to a complete stop. Driving is a compulsory activity for most people and the numbers of vehicles as well as the number of accidents are continuously increasing. These accidents are mostly caused by the delay of the driver to hit the brake pedal [1].

The automatic braking is a technology for automobiles to sense an imminent collision with another vehicle, person or obstacle and to apply brakes to slow the vehicle without any driver input. Sensors are used to detect other vehicles or obstacles, these can be radar, video, infrared, laser, ultrasonic or other sensing technologies [2].

\section{LITERATURE SURVEY}

In conventional vehicles, there are different mechanisms operated for braking system such as mechanical, hydraulic, and pneumatic systems. All these braking mechanisms receive the input signal directly from the driver by hitting the brake pedal. Thus, braking of vehicles is totally manual operated. So, if the driver fails to see the obstacle in front of his driving vehicle or fails to apply proper braking force on the brake pedal, he may lose the control of his vehicle, leading to an accident. This leads to the appearance of intelligent braking systems. Intelligent braking systems have been produced and developed in recent research such as pre-crash safety system with pedestrian collision avoidance and automatic braking system with a pneumatic pumper; these systems depend on controlling the speed of a vehicle by using a suitable actuator and control unit. 
The hydraulic brake system is one of the brake systems that are used in vehicles such as mechanical and pneumatic brake system. Hydraulic brake system is used as the main braking system on almost all passenger vehicles and light trucks. Hydraulic brake uses brake fluid to transmit force when the brake is applied. Pneumatic brake system uses compressed air, which is stored in tanks, to produce the force that applies the brake at each wheel. The main difference between hydraulic brake system and pneumatic brake system is the medium used to transmit power. In hydraulic brake liquid/oil is used to transmit power, whereas in pneumatic compressed gas (generally air) is used to transmit power. Due to this difference there are many things that differ between the two systems. So, the hydraulic braking system will be use in this work among three systems because [3]:

- The brake force generated by hydraulic braking system is very high as compared to the mechanical braking which is a very important factor for today's super and hyper series of vehicles.

- Frictional wear and tear in case of mechanical braking system was very high due to the involvement of many moving parts, which is very well reduced to the optimum level with the introduction of hydraulic braking system which has very fewer moving parts as compared to the mechanical one.

- Brake failure chances in case of hydraulic braking system are very less as compared to the mechanical system due to direct connection between the actuator (brake pedal or lever) and the brake disc or drum.

- Design complexity in case of mechanical braking was very high which is reduced with the introduction of hydraulic braking system which has simple and easily assembled design.

- The maintenance in case of mechanical braking system was high due to the involvement of complex and a greater number of members which is not a problem with the hydraulic braking system as it has simple design with less moving parts.

- Equal braking action on all wheels and Simple in construction.

Many research works investigated the development of automatic brake system such as; Eung Soo Kim [4] that designed and fabricated an auto-braking system for pre-crash safety. This system was designed to keep a constant distance between the front car and driver car. It was fabricated using FPGA (field-programmable gate array) and VHDL (very high-speed integrated circuit hardware description language). The sensors embedded in vehicle detect the road environment such as driver's vehicle velocity, distance from the front vehicle and surroundings vehicles using infrared sensor and ultrasonic sensor. It displays the distance between the two vehicles and the speed of the driver's vehicle. A servo motor is used to move the brake pedal. The brake pedal was controlled by PWM (pulse width modulation) signal, which differs according to the distance between the front car and driver's car.

Firoz Syed [5] presented an intelligent mechatronic braking System. The main target of the system is to run automatic braking due to obstacles when the sensor senses the obstacles. The braking circuit function is to break the car automatically after the received signal from the sensor. The system includes an ultrasonic wave emitter provided on the front portion of the car and emitting ultrasonic waves frontward in a predetermined distance. An ultrasonic receiver is also placed on the front portion of the car that operatively receives the reflected ultrasonic wave signal. The reflected wave (detected pulse) measure the distance between the obstacle and the vehicle. Then a microcontroller (ATMEGA32) is used to control the speed of the vehicle based on the detected pulse information to push the brake pedal and apply the brake to the car stupendously for safety purpose.

P. Poongodi [6] studied the need for safety of vehicles by reducing the impact of a crash by applying a smooth or partial braking with the help PIC 16F877a microcontroller. The driver's risk of sensing the object from a particular distance and being unable to notice it within the certain limit, in such conditions this work was designed. Once the similar situation will be faced the acceleration of the vehicle will be directly controlled without any disturbing to the safe throttle (actuation mechanism) of the vehicle, the designed machine itself takes the control of acceleration pedal if the brake is not applied within the predetermined distance.

K. Chirantana [7] has proposed a technology of collision warning with automatic braking system for electric cars, this system is used to reduce vehicle speed and stop it when the distance between driver vehicle and front vehicle become limited. This system warns the driver in case of collision existence and along with brake support for collisions with other vehicles. Collision detection is done by using the ultrasonic sensor and stop indication using a flashing LED and LCD display. When an ultrasonic sensor detects the subject such as vehicle or pedestrian, it sends the signal to a microcontroller which sends a signal to brake circuit. Brake circuit consists of a servo motor and lever that is connected to the brake pedal when servo motor received the signal from the microcontroller the arm of the servo motor rotates the brake, a pedal is actuated and the brake is applied.

R. S. Krishnaveni [8] has described a system based on an intelligent vicinity adapter for automobiles. The main objective of this system is to help the driver to slow down the vehicle at breaking speed in order to prevent accidents. The main components of this system are the ultrasonic sensor, IR sensor, microcontroller (ATmega328P) and servo motor. The distance between the driver vehicle and the object such as vehicle or person is measured by the ultrasonic sensor. Moreover, the happenings of side scrape on the vehicle could be prevented, this can be done using IR sensor which detects break beam and also indicates the intrusion of passenger's head and hands through a window and door during vehicle motion. The ultrasonic sensor detects distance, then it 
sends signals to the microcontroller, microcontroller processed signals to control the servo motor. Servo motor rotates when it received the signal from the microcontroller to rotate brake pedal and control the speed of the vehicle according to it.

S. Wasnik [9] has proposed the automatic pneumatic bumper. The objectives of this system are to decrease the rate of the car accident, increase the response of the braking system, and increase the sureness of people who fear from an accident. The main components of this system are the IR sensor, solenoid valve, pneumatic cylinder, composer and a control unit. When the obstacle found in front of the vehicle, the IR sensor sends the signal to the control unit, which sends the signal to the solenoid valve, solenoid valve consists of one input and two outputs, the input is connected to the composer and the two outputs are connected to the wheel cylinder, when the solenoid valve receives the signal from the control unit it is activated and the brake is applied, whenever the driver does not hit the brake.

In this research, an appropriate mechanism is used to control the brake system automatically, this system different the previous systems because some of them used servo motor to operation brake pedal according to signals incoming from microcontroller, and others used air compressor to control a pneumatic brake system, but a suitable electric pump was used to provide a pressurized fluid flow and two solenoid valves to control a direction of brake fluid in hydraulic brake system.

\section{DESIGE OF AUTOMATIC EMERGENCY BRAKE}

\subsection{Braking Distance and Time Analysis.}

Assuming the vehicle acceleration a is constant and using $\mathrm{Vi}$ is the initial velocity, the final velocity $\mathrm{Vf}, \mathrm{t}$ is travel time by car and $\mathrm{D}$ is the travel distance. By looking at the four principal equations in kinematics [10], theoretical final velocity is obtained by:

$$
V_{f}=V_{i}+a t
$$

The travelled distance D is obtained by:

$$
D=V_{i} t+\frac{1}{2} a t^{2}
$$

The final velocity can be also obtained using:

$$
V_{f}^{2}=V_{i}^{2}+2 a D
$$

Using equation (1), (2), and (3), the travel distance DT can be calculated as:

$$
D_{T}=\frac{V_{f}^{2}-V_{i}^{2}}{2 a}
$$

The stopping distance Ds (the distance traveled by car before stopping directly) as the car eventually stops (Vf is zero) can be calculated as:

$$
D_{s}=\frac{-V_{i}^{2}}{2 a}
$$

For vehicle with conventional braking system, the longitudinal deceleration a is one of the main parameters of the braking system, which can be calculated with formula

$$
a=\phi_{x} g
$$

where $\phi_{x}$ is the longitudinal coefficient of adherence of the tires with the running path and $\mathrm{g}$ is the gravitational acceleration $(\mathrm{g}=$ $9.81 \mathrm{~m} / \mathrm{s} 2$ ). In the situation of actual cars, the maximum coefficient of adherence has the value $\varphi \mathrm{x}=1-1.2$ [11], if braking takes place on a running path with dry asphalt, situation when the deceleration of old cars with tires produced at the present moment can reach values in the range 7.35- 9.3 [m/s2]. From equations (1) and (4) one can get the formula for time as:

The stopping time can be also calculated as:

$$
t=\frac{2 D}{\left(V_{f}+V_{i}\right)}
$$

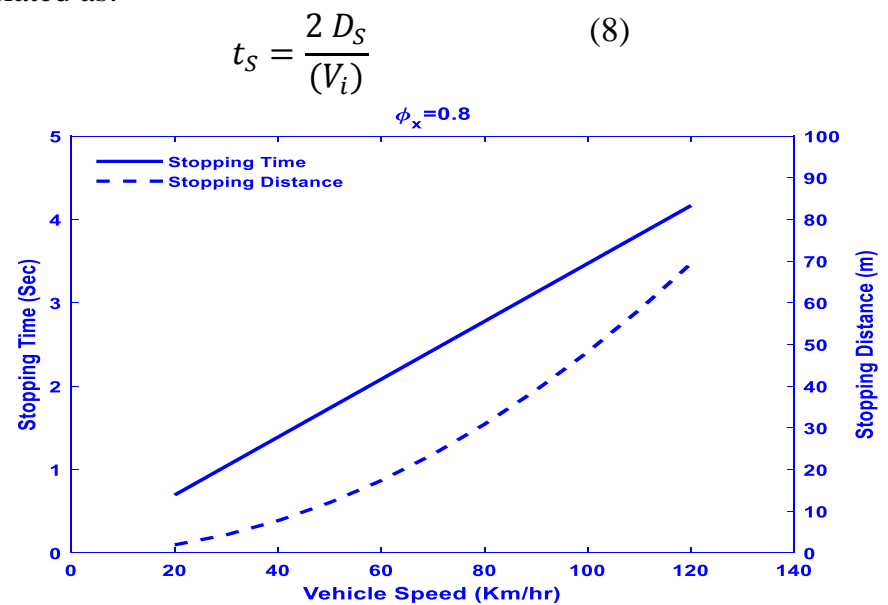


Figure 1. Variation of stopping time, and stopping distance with vehicle speed at $\phi_{x}=0.8$.

In case of two following Vehicles and based on an earlier work [12-15], the collision avoidance distance (DCA) required by braking is set to be equal to the difference between host vehicle braking distances, DHV,br and preceding vehicle braking distance, DPV,br, using equation 4.

where, $\mathrm{Vh}=$ host vehicle velocity, $\mathrm{VP}=$ lead vehicle velocity, ah = host vehicle maximum deceleration rate, aP $=$ lead vehicle maximum deceleration rate. The braking distance can be calculated as:

$$
D_{B r}=D_{h B r}-D_{P B r}=-\left(\frac{V_{i h}^{2}}{2 a_{h}}-\frac{V_{i P}^{2}}{2 a_{P}}\right)
$$

Where, $D_{h B r}$ and $D_{P B r}$ are the braking distance of the host and preceding vehicle respectively. If it is assumed that ah and aP are equal to a, equation (10) can be simplified as:

$$
D_{B r}=\frac{-V_{i h}^{2}+V_{i P}^{2}}{2 a}
$$

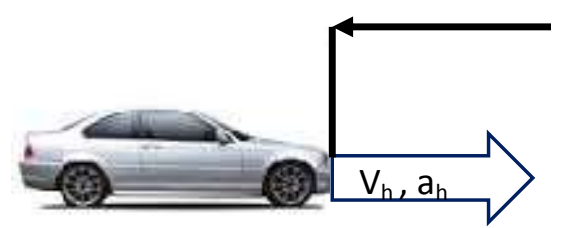

Host Vehicle

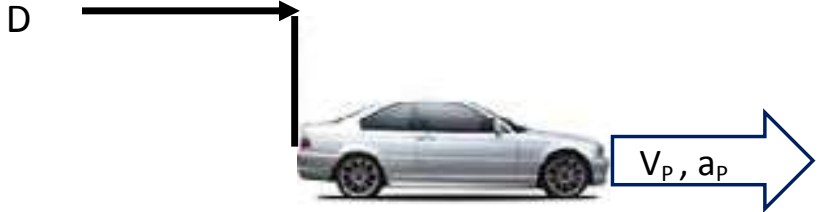

Preceding Vehicle

Figure 2. Relative motion representation between the host and preceding vehicles.

Unfortunately, equation (10) does not cover all scenarios. For instance, this equation will not give the actual DHV required to avoid a collision with a preceding vehicle when the initial velocity of host vehicle is higher than that of preceding vehicle, and the preceding vehicle braking distance is larger than host vehicle braking distance. An example is given to clarify this. Assume that host vehicle is traveling with a speed of $25 \mathrm{~m} / \mathrm{s}(=90 \mathrm{~km} / \mathrm{h})$. Preceding vehicle is traveling with a speed of $17 \mathrm{~m} / \mathrm{s}(=61.2 \mathrm{~km} / \mathrm{h})$. If preceding vehicle begins decelerating with $4 \mathrm{~m} / \mathrm{s} 2$ and host vehicle is capable of braking with $8 \mathrm{~m} / \mathrm{s} 2$, equation 5 would give following DHV required to avoid collision with preceding vehicle by braking. The $\mathrm{DBr}=-3.5 \mathrm{~m} / \mathrm{s} 2$, note that this signifies that host vehicle would not be required to begin braking in order to avoid collision with preceding vehicle. It is obvious that this is not the case in real life. The driver reaction time and system delay can easily be accounted for if desired. The DCA required by braking is then:

$$
D_{B r}=-\left(\frac{V_{i h}^{2}}{2 a_{h}}-\frac{V_{i P}^{2}}{2 a_{P}}\right)+V_{r} t_{r}+V_{r} t_{S}
$$

where $\mathrm{Vr}$ is the relative velocity, tr is driver reaction time and ts is system response. The relative velocity can be calculated as

$$
V_{r}=V_{i h}-\left(V_{i P}+a_{P}\left(t_{r}+t_{S}\right) / 2\right)
$$

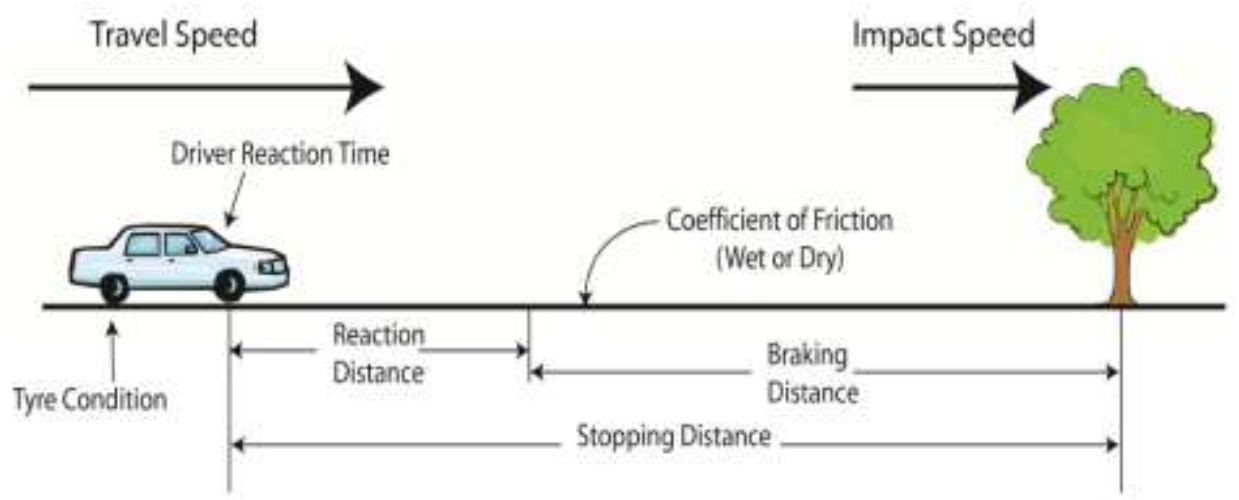

Figure 3. Key factors in stopping distance.

For an obstacle as shown in Figure $3\left(V_{i P}=0\right)$, the DCA required by braking is

$$
D_{B r}=-\left(\frac{V_{i h}^{2}}{2 a_{h}}\right)+V_{i h} t_{r}+V_{i h} t_{S}
$$

For real vehicle and avoiding the driver as well as the system responses, the actual needed times is the actual braking time. The system braking distance can be calculated as: 


$$
D_{B r}=-\left(\frac{V_{i h}^{2}}{2 a_{h}}\right)
$$

Also, the rate of change of the velocity with respect to distance travelled can be calculated using equation (3) as:

$$
\frac{d V_{f}}{d D}=\frac{a}{\sqrt{V_{i}^{2}+2 a D}}=\frac{a}{V_{f}}
$$

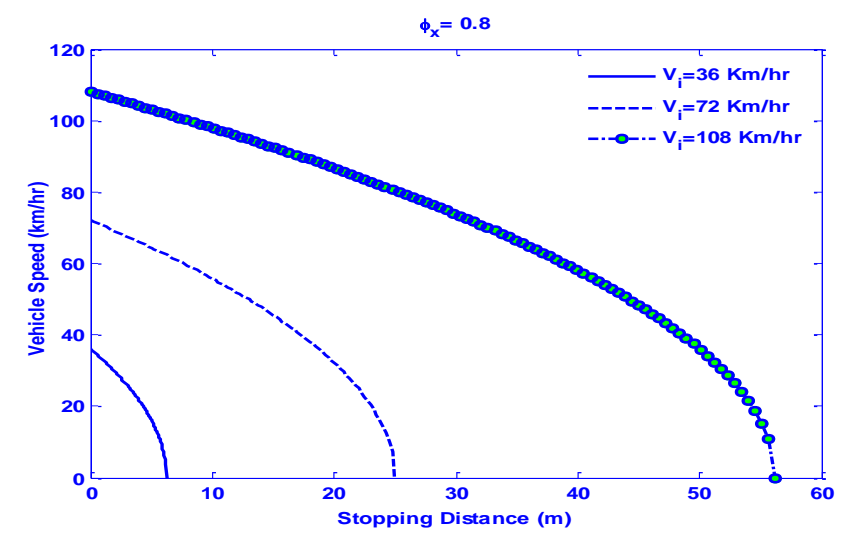

Figure 4. Vehicle speed versus distance travelled at $\phi=0.8$.

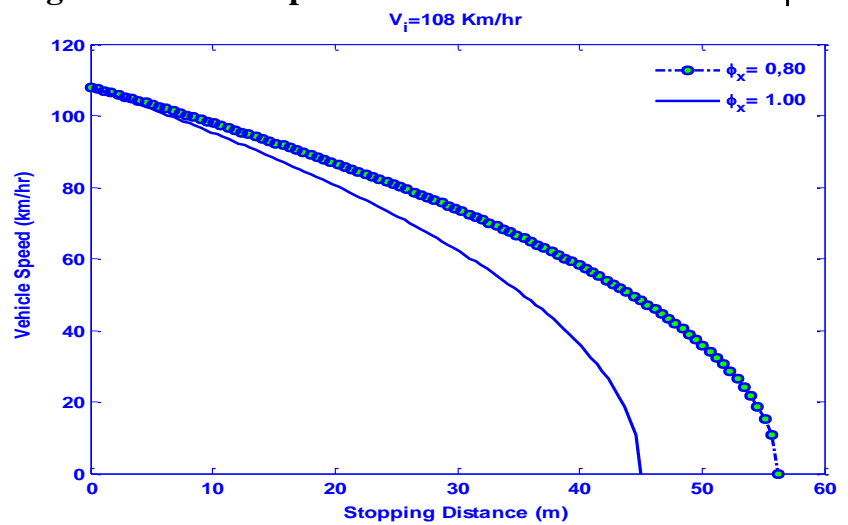

Figure 5. Vehicle speed versus distance travelled at different road friction coefficient $(\phi)$.

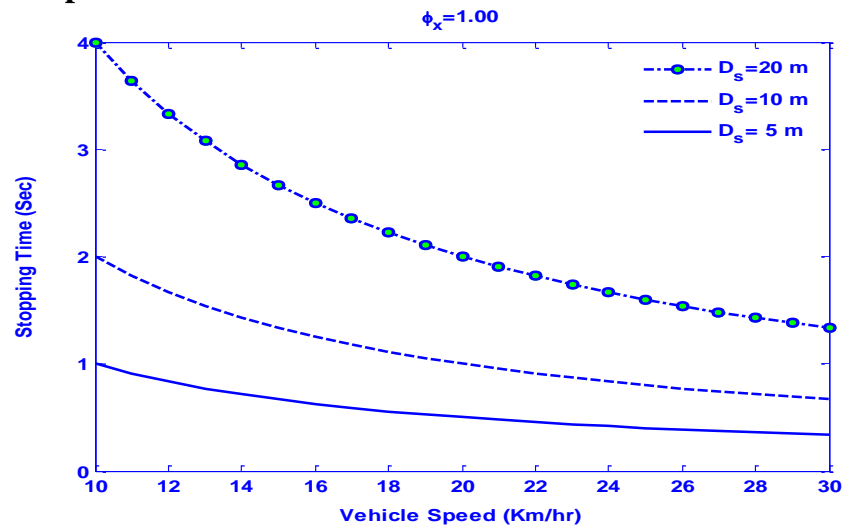

Figure 6. Vehicle speed versus stopping time at different allowable stopping distance $\left(\mathrm{D}_{\mathrm{s}}\right)$.

\section{NEW SYSTEM COMPONENTS and WORKING PRINCIPLE}

This system consists of two Ultrasonic Transducers as distance measurement sensors, kit of an electronic control unit to manage the signal input and output of sensor, hydraulic circuit, two solenoid control valves (one normally closed while the other is normally opened) and single acting hydraulic cylinder. The sensor is having 12 volts supply and it can measure hurdle up to $10 \mathrm{~m}$. In this section, the braking system test rig which consists of mechanical components, electronic components, and the control program are briefly explained.

\section{4-1 Mechanical Components of The Test Rig}

The mechanical components of the test rig are the drum brake, brake pedal, master cylinder, brake booster, solenoids valves, hydraulic pump, and an electric motor. A drum brake test rig is designed to provide the necessary rotational speed and applied 
pressure to the real braking applications. A brake pedal is used to transfer braking power from the driver's foot to the main cylinder and then to the wheel's cylinders, and it is also used to enlarge the braking force by an appropriate proportion. A brake booster functions to give more braking power with minimum pressure on the brake pedal. The brake booster is located between the brake pedal and the master cylinder. Solenoid valves are used to control the direction and pressure of brake fluid. Two types of solenoid valves are used, one solenoid valve is normally open, which is installed after brake pedal, another solenoid valve is normally closed, which is installed after the electric pump.

The electric pump is an electric device used to pump the brake fluid with the appropriate amount and pressure to stop rotation of drum brake, it operating over pressure $30 \mathrm{bar}$ and maximum volume flow rate $1 / 4 \mathrm{~L} / \mathrm{sec}$. An electric motor is connected to a drum brake by a suitable rod, which is rotating the drum brake by variable speeds, electric motor capacity is 2 HP. Figure 7 shows a photo of the test rig.

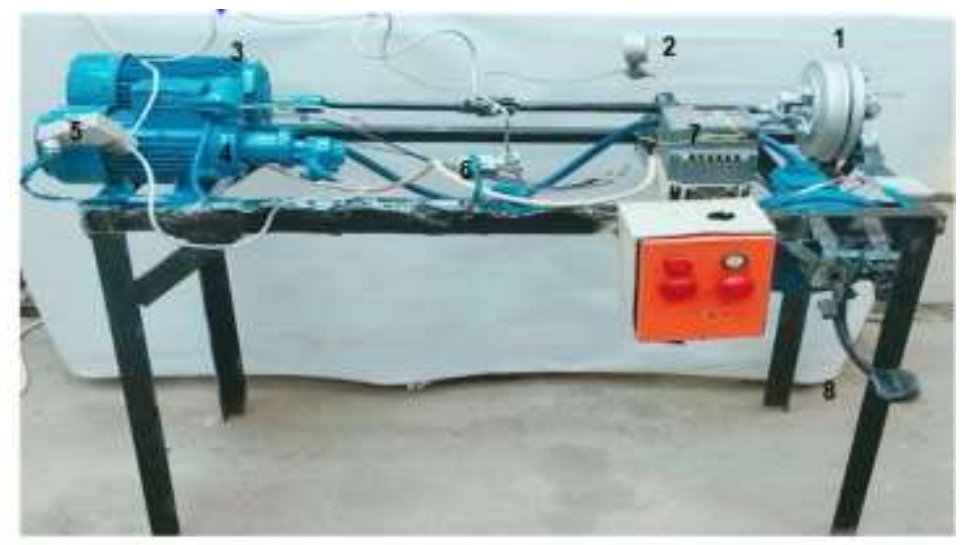

Figure 7. A photo of the test rig.

1- Drum brake, 2- Pressure gauge, 3- Electric motor, 4- Electric pump, 5- Solenoid valve normal closed, 6- Solenoid valve normal open, 7- Inverter, 8- Brake pedal.

\section{4-2 Electronic Components of Automatic Hydraulic Braking System}

As shown in Figure 8 the Electronic components used in the test rig are an Arduino Uno board, Ultrasonic sensor, and an Electric relay. An Arduino Uno board of a microcontroller [10] which used to receive signals from ultrasonic sensor and process it, then send signals to electric relays. The sensor uses Input/output trigger for $10 \mu$ s high-level signal, it automatically sends eight $40 \mathrm{kHz}$ and detects for pulse signal and note down the time taken for waves to bounce back. Test distance $=$ travel time the $\times$ velocity of sound as shown in Figure 9. Knowing the speed of sound, the sensor determines the distance of the target and sets its outputs accordingly. It provides a range of $2-450 \mathrm{~cm}$ non-contact measurement function, the ranging accuracy can reach to $3 \mathrm{~mm}$ [11].

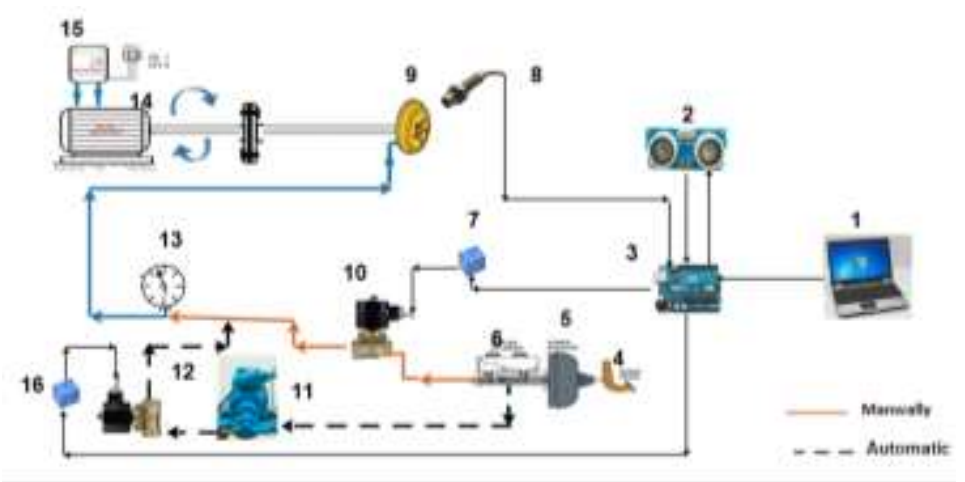

Figure 8. A schematic diagram of the test rig.

1- Computer 2- Ultrasonic sensor 3- Arduino Uno Microcontroller 4 - Brake pedal 5- Brake booster 6-Master cylinder 7Relay 8- RPM sensor 9- Drum brake 10- Solenoid valve normal open 11- Electric pump 12- Solenoid valve normal closed 13Pressure gauge 14- Electric motor 15- Inverter 16- Relay.

An Electronic relay acts as a switch which is turned on and off using a signal. It is controlled through the digital I / O port, such as solenoid valves, lamps, motors, and other high current or high voltage devices. It used to control open or closed solenoids valves by signals from the microcontroller. To perform the measurements after 4 meters distances, Senix ultrasonic (RS- 
232) sensors are used, which provides a measurement rang of $4-1500 \mathrm{~cm}$ of non-contact measurement function.

(1) Ultrasonic pulse transmitted from sensor

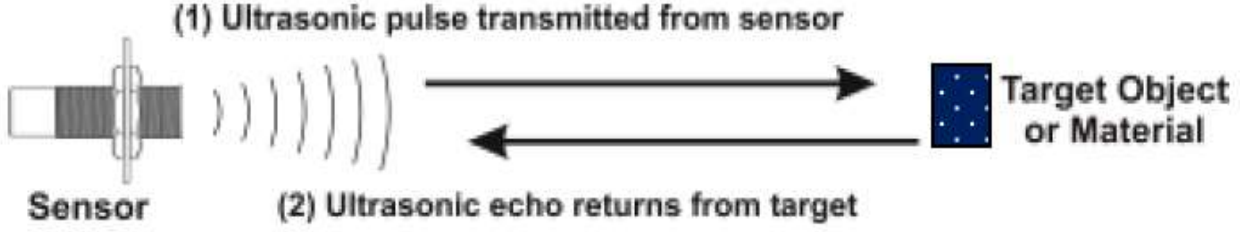

Figure 9. A schematic diagram of Ultrasound working principles.

\section{4-3 Automatic Barking Control Strategy}

Ultrasonic sensor is operated all the time during driving producing ultrasonic transmitted sound waves, when these waves found an obstacle (vehicles or human) within a certain distance, the sound wave is reflected, the ultra-sonic emitter sends signals to the microcontroller, which processes it. If the measured distance between the obstacle and the vehicle is less than the desired distance which can be adjusted, the control unit sends a signal to activate the electronic relay to open the solenoid valve normally closed and closed the solenoid valve normally open. The hydraulic pump draws the hydraulic oil from the reservoir and presses the fluid in the pipes to the drum brake piston which push the drum shoes and stop the vehicle. After stopping the vehicle, the activated solenoid valves return to their original positions and the hydraulic oil go back normally to reservoir. Figure 10 shows flow chart of the normal and active braking system working, Figure 11 shows a schematic diagram of the control program and Figure 12 shows all components of test rig.

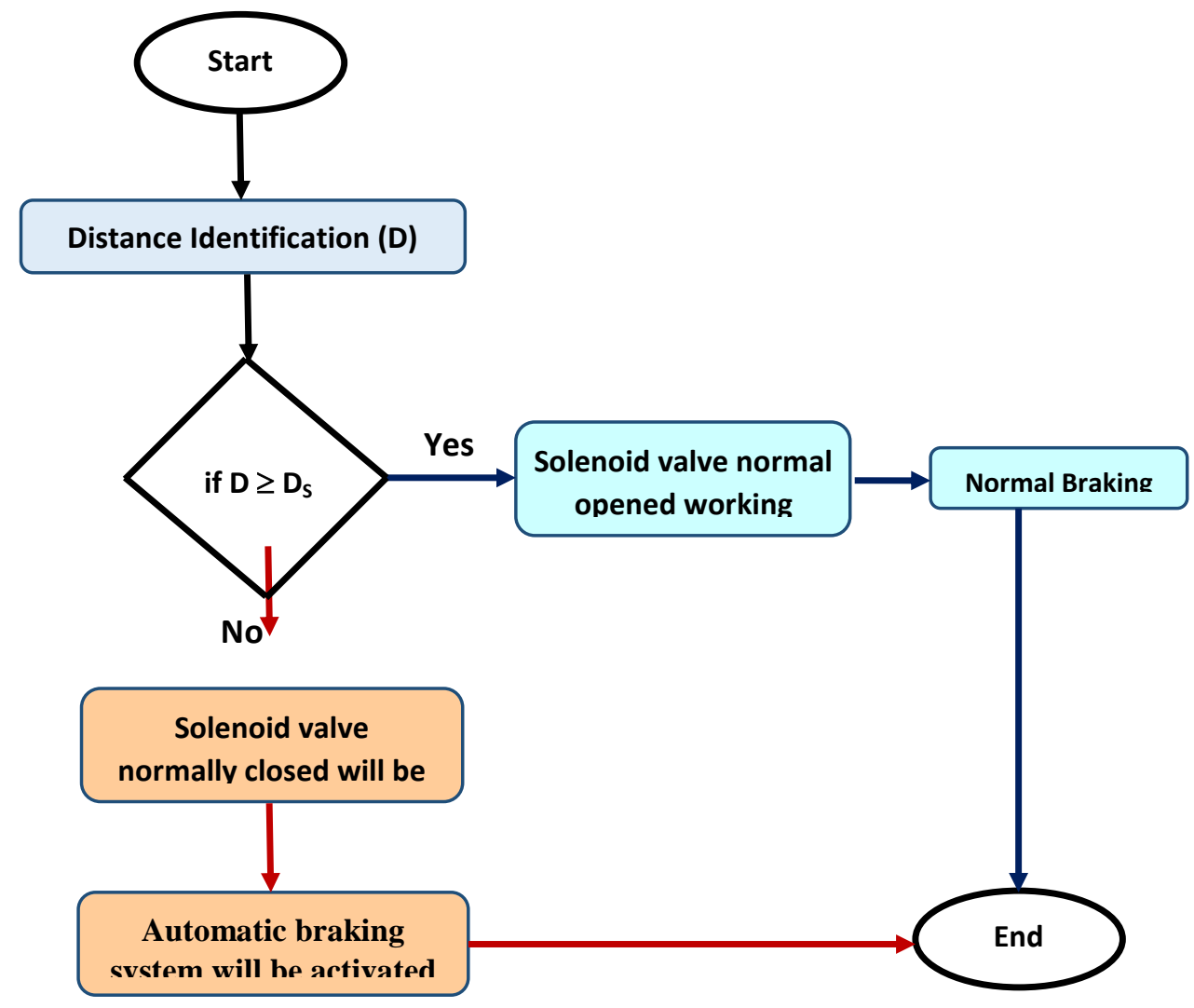

Figure 10. Flow chart of the normal and active braking system working. $\mathrm{D}_{\mathrm{s}}$ is the predefined stopping distance. 


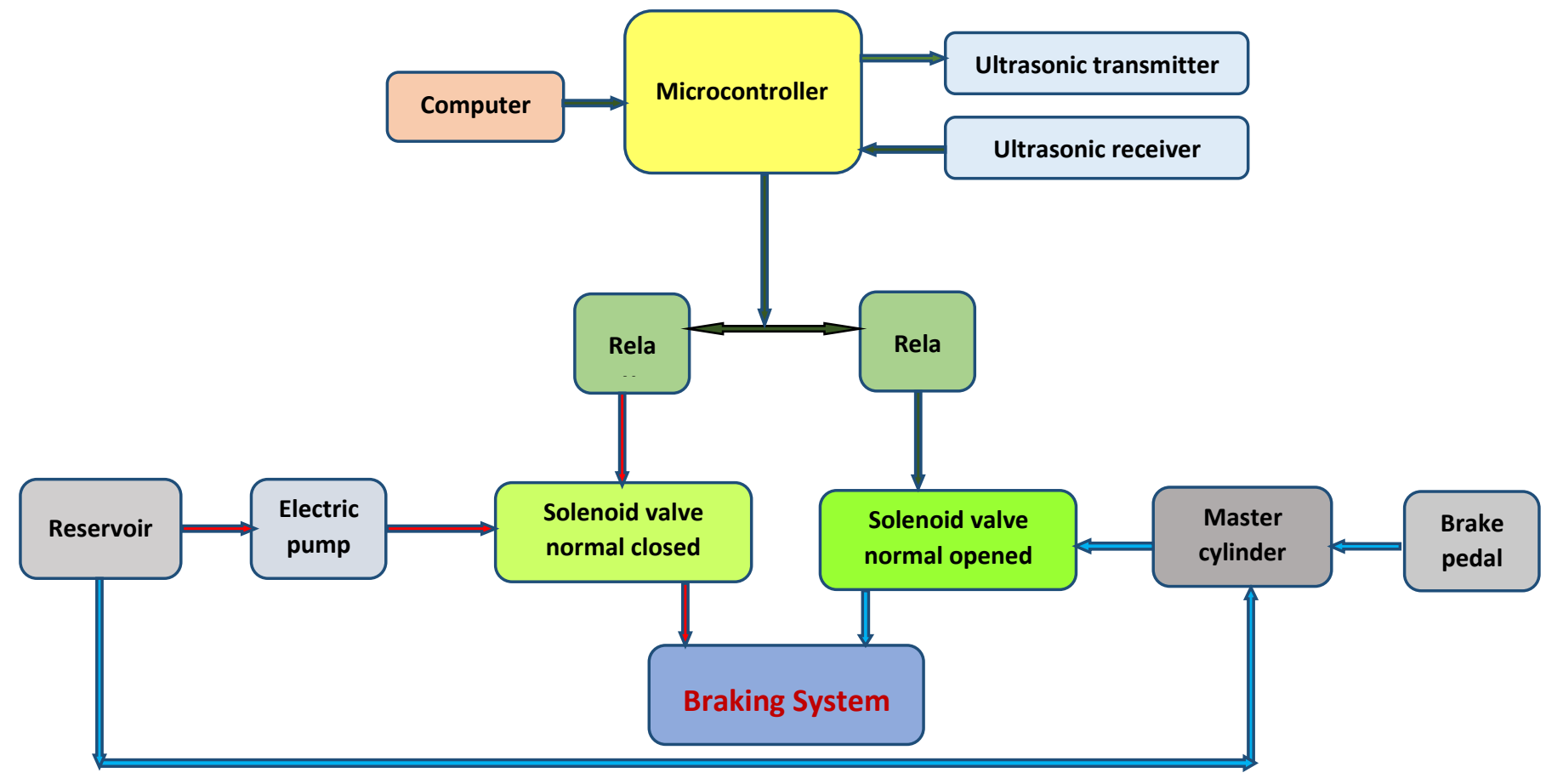

Figure 11. Block diagram of normal (blue) and/ or automatic (red) braking system working methodologies.

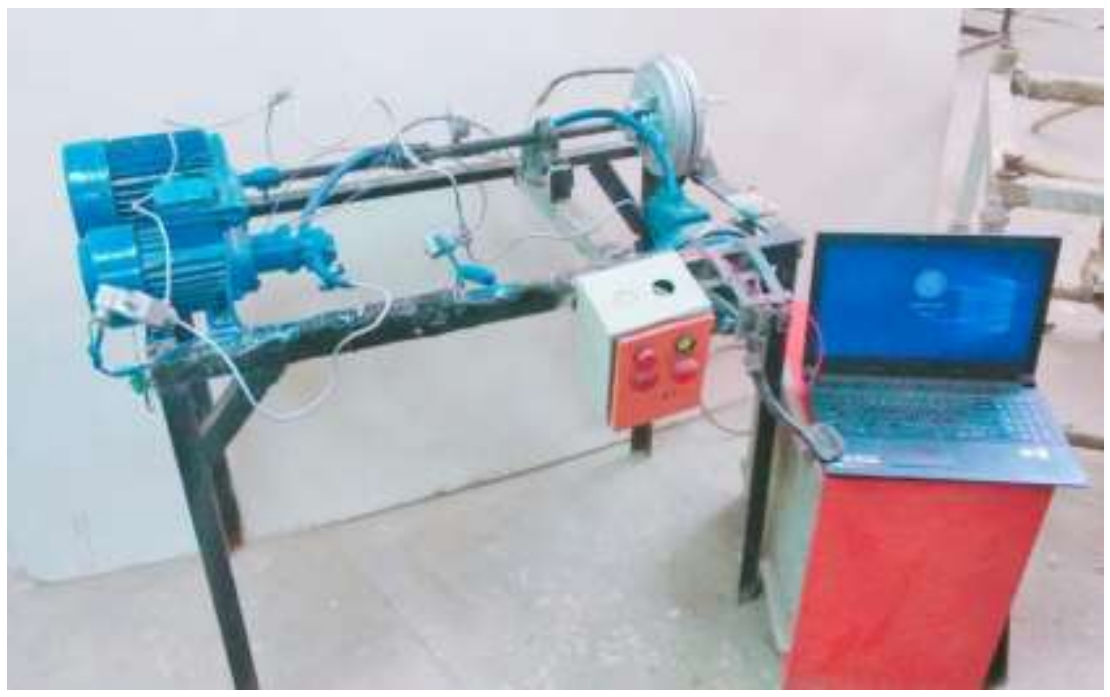

Figure 12. All components of test rig.

\section{4-4 New Automatic Hydraulic Braking System Working Methodology}

This system works manually and mechanically together so that the driver can use the brakes to stop the vehicle during the safe suspension. If there is an obstacle (a person or another car) and the driver cannot use the brake at the right time, the vehicle is stopped automatically.

The ultrasonic sensors work continuously with the start of the vehicle, when there is a barrier located at a distance, the ultrasound waves return to the receiver part of the feedback signals in the sensor and sent to the electronic control unit. The controller receives these signals, processes them and calculates the distance between the vehicle and the obstacle in front of it. If this distance is less than or equal to the safe stopping distance (which can be controlled by the control unit), the controller sends appropriate signals to 2 Electric Relays. The first Relay is connected to the electrical circuit of the normally closed solenoid valve which is connected to the hydraulic pump, while the other Relay is connected to the electrical circuit of the normally open solenoid valve that is installed after the original master as shown in Figure 11. This signal changes the solenoid valve which is connected to oil pump from normally closed to open, the oil is transferred from the oil pump to the hydraulic brake circuit. At the same time, the solenoid valve which is normally opens and it is connected to main brake master from open to closed to prevent oil from returning to it. Thus, the pressure inside the hydraulic circuit of the brake system increases and the braking process is done automatically without the driver intervening according to the distance in front of the vehicle. 


\section{TECHNICAL ASSESSMENT OF DEVELOPED MODULE}

The measured and calculated stopping time is presented in Figure 13. The measurements are performed at five distances between the system and an obstacle, these distances are 2, 3, 4, 6, 8 and 10 meters. The stopping time is measured at five different vehicle speeds; these speeds are 70, 80, 90,100, and $110 \mathrm{Km} / \mathrm{hr}$. As can be seen from these results, there are excellent agreement between measured and predicted results. Based on an error analysis, the noticed errors have been found to be between $1.07 \%$ at $70 \mathrm{~km} / \mathrm{hr}$ and $2.17 \%$ at $110 \mathrm{~km} / \mathrm{hr}$.

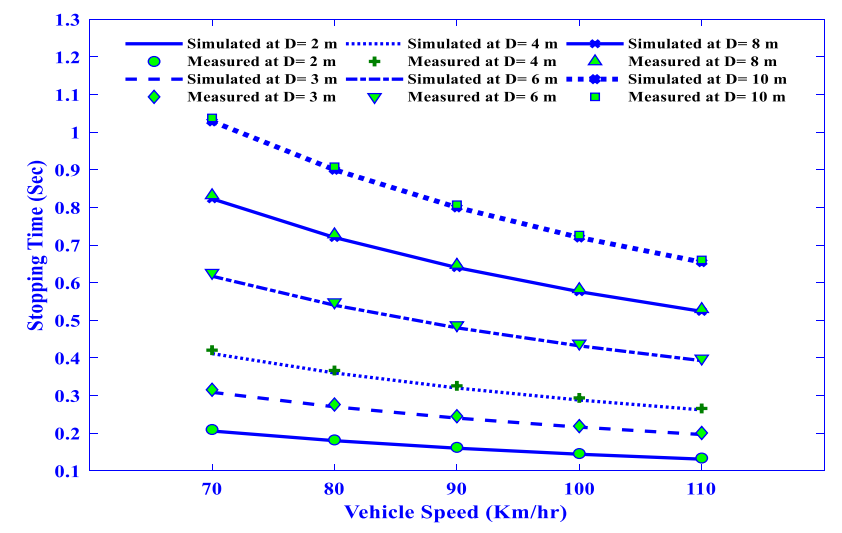

Figure 13: Measured and Predicted stopping time versus vehicle speed at different allowable stopping distance.

\section{CONCLUSION}

In this paper, we used a unit that simulates and it is similar to the reality of working the vehicle on the road. This system operated manually and automatic in parallel, when the vehicle reached a certain distance, if the driver does not respond and hit the brake pedal in a right time, this system can automatically stop the vehicle without driver input. This system consists of an ultrasonic sensor, microcontroller, electric pump, and two solenoids valves, where ultrasonic used to measure the distance between an obstacle and vehicle and send signals to the microcontroller, microcontroller received these signals and processed it, then send signals to rely, to activated solenoids valves and braking is done automatically. From results we concluded, this system cheap, easy maintenance, a control system which has been used simple and the performance of the system is excellent.

\section{REFRANCES}

[1] H. seung Choi and W. keun Hyun, "A low cost map building sensor system for mobile robot" Industrial Informatics, 2008. INDIN. 6th IEEE International Conference on, 2008, pp. 448-452.

[3] M. Omae, T. Ogitsu, N. Honma, and K. Usami, "Automatic driving control for passing through intersection without stopping,” Int. J. Intell. Transp. Syst. Res., vol. 8, no. 3, pp. 201-210, 2010.

[2] C. Unsal and P. Kachroo, "Sliding mode measurement feedback control for antilock braking systems," IEEE Trans. Control Syst. Technol., vol. 7, no. 2, pp. 271-281, 1999.

[4] E. S. Kim et al., "Fabrication of auto-braking system for pre-crash safety using sensor," in Future Generation Communication and Networking Symposia, 2008. FGCNS'08. Second International Conference on, 2008, vol. 4, pp. 4954.

[5] G. V Sairam, B. Suresh, C. H. S. Hemanth, and K. Krishna, “Intelligent Mechatronic Braking System,” vol. 3, no. 4, pp. 3-8, 2013.

[6] M. Bin Tahir and M. Abdullah, "Distance Measuring (Hurdle detection System) for Safe Environment in Vehicles through Ultrasonic Rays,” Glob. J. Res. Eng., vol. 12, no. 1-B, 2012.

[7] J. H. Lemelson and R. D. Pedersen, "GPS vehicle collision avoidance warning and control system and method." Google Patents, 2002.

[8] D. C. H. Shaw and J. Z. Z. Shaw, "Vehicle collision avoidance system.” Google Patents, 1996.

[9] L. M. Senatus, "Receptor for Advanced Glycation End Products (Ager) and Diaphanous-1 (Drf1) Suppress Regression of Diabetic Atherosclerosis," New York University, 2016.

[10] Robert Bosch GmbH, 2002. Bosch Automotive-Handbook.

[11] Mitunevicius V., 1999 - Application of braking responses of vecles for expert's examinations of vehicles. Im Transbal-tica99. Collection of scientific reports of the International Conference (Transbaltica-99,tarptautines konferencijos moksliniu pranesimu rinkinys, Vilnius, 8-9 April 1999).Vilnius Technika (in Lithuanian), p.221-226. 
[12] J. Jansson: Tracking and Decision Making for Automotive Collision Avoidance.Linköping University, SE-581 83 Linköping, Sweden, 2002.

[13] P. Seiler, B. Song and J. K. Hedrick: Development of a Collision Avoidance System. SAE paper No 98 PC-417.

[14] E. Wennerström, S. Nordmark and B. Thorvald: Fordonsdynamik Royal Institute of Technology, Department of Vehicle Engineering, Stockholm, Sweden, 1999.

[15] Homepage of FARS - Fatality Analysis Reporting System < http://www-fars.nhtsa.dot.gov/ > (2004-09-29).

[10] L. M. Senatus, "Receptor for Advanced Glycation End Products (Ager) and Diaphanous-1 Regression of Diabetic Atherosclerosis," New York University, 2016.

(Drf1) Suppress

[11] S. Shinde Aniket, P. Hivrekar Akshay, S. Dherange Nitin, and B. Shegar Ganesh, "Smart Breaking System with Pneumatic Bumper,” Int. J. Eng. Sci., vol. 10329, 2017.

[12] T. Wada, S. Doi, and S. Hiraoka, "A deceleration control method of automobile for collision avoidance based on driver's perceptual risk," in Intelligent Robots and Systems, 2009. IROS 2009. IEEE/RSJ International Conference on, 2009, pp. 4881-4886.

[13] P. Thammakaroon and P. Tangamchit, "Improvement of forward collision warning in real driving environment using machine vision,” Int. J. Intell. Transp. Syst. Res., vol. 8, no. 3, pp. 131-139, 2010.

[14] K. R. Dhanya and M. R. Jeyanthi, “Advanced automatic braking system with sensor fusion concept,” Int. J. Emerg. trends Eng. Dev. ISSN, pp. 2249-6149, 2012.

[15] S. Jitesh, “ANTILOCK BRAKING SYSTEM (ABS),” Int. J. Mech. Eng. Robot. Res., vol. 3, no. 4, p. 253 , 2014. 